\title{
Exploring durability of interfaces in flax fibre/epoxy micro-composites
}

\author{
Antoine Le Duigou ${ }^{\mathrm{a}, *}$, Peter Davies ${ }^{\mathrm{b}}$, Christophe Baley ${ }^{\mathrm{a}}$
}

\author{
a LIMATB Laboratoire d'Ingénierie des matériaux de Bretagne, Equipe Polymères et Composites, Rue de Saint \\ Maudé BP 92116, 56321 Lorient Cedex, France \\ b IFREMER Materials and Structures Group, Brest Centre, BP 70, 29280 Plouzané, France \\ *: Corresponding author : Antoine Le Duigou, tel.: +33 297874586 ; fax: +33297874588 ; \\ email address : antoine.le-duigou@univ-ubs.fr
}

\begin{abstract}
:
The influence of wet aging on the behaviour of flax/epoxy micro-composites composed of single flax fibres embedded in epoxy micro-droplets has been studied. Interfacial shear strength has been examined by debonding the micro-droplets. The apparent interfacial shear strength decreases with immersion time in water, dropping rapidly during the first $15 \mathrm{~min}$ of immersion then stabilizing. Drying samples after short immersion periods allows recovery of properties, indicating a plasticization mechanism. For longer immersion times irreversible degradation is observed. Scanning electron microscopy reveals fibre surface peeling, indicating that an internal interface within the fibre is weaker than the fibre/matrix interface after aging. A simple descriptive model has been used to identify diffusion kinetics, with a critical diffusion time corresponding to a change in degradation mechanism.
\end{abstract}

Keywords: A. Flax fibres ; A. Environmental degradation ; B. Fibre/matrix bond 


\section{Introduction}

The current environmental situation is encouraging designers to take environmental impact into account in addition to conventional criteria for material selection [1], such as mechanical properties, weight, cost, etc. The eco-design approach, which uses tools such as life cycle analysis, has shown the environmental advantages of natural fibre reinforcements $[2,3]$ and biocomposites (natural fibre embedded in a biopolymer matrix) [4, 5]. Le Duigou et al. [4] have shown that the lifetime of flax/Poly(L-Lactic) Acid biocomposites has a strong influence on their global environmental impact. Understanding the aging mechanisms of these materials is therefore of primary importance.

Aging in a humid environment affects the matrix, the fibres and the fibre/matrix interface of composite materials. The latter may control the long term durability, and Bordès [6] showed that the diffusion of water at a polymer/substrate interface may be much faster than that in the polymer alone. Kinloch [7] suggested that interface degradation may require a critical water level, while Cognard et al. [8] proposed that water condensing at interfaces could result in osmotic pressure and lead to interface debonding.

Adherence is the sum of different contributions (chemical bonds, secondary interaction forces (van der Waals, acid/base...), interdiffusion, residual stresses, mechanical interlocking). These interactions control the load transfer between fibre and matrix and hence the global composite properties. The quality of the fibre/matrix interface also influences the water uptake of the composites. For example, Joseph et al. [9] showed that improved adherence between sisal fibres and PolyPropylene via chemical treatments reduced their weight gain due to water sorption, by reducing capillary water ingress.

Most published studies have focused on macroscopic properties, nevertheless understanding the direct interfacial damage mechanisms requires micromechanical studies (fragmentation, pull-out or micro-droplet debonding). These provide information on samples which are similar to unidirectional plies, at least with respect to the influence of the components in the unaged state [10]. Moreover, a micromechanical approach can be used to examine directly the effects of hygrothermal aging on the strength of the interfacial bond. For example, debonding of micro-droplets was used by Zinck et al. [11] who showed a decrease in critical strain energy release rate during the first 50 hours of aging $\left(60^{\circ} \mathrm{C}\right.$ and $\left.98 \% \mathrm{RH}\right)$ of glass/epoxy systems. Pandey et al. [12] showed a drop in apparent shear strength on carbon/epoxy composites, from 88 to $80 \mathrm{MPa}$ after immersion in boiling water for $48 \mathrm{~h}$. They explained this by radial stresses relaxation during immersion. Gaur et al. [13] also noted a drop in the properties of glass/epoxy and Kevlar ${ }^{\circledR} /$ epoxy systems at $100^{\circ} \mathrm{C}$ and $85 \% \mathrm{RH}$. These changes were completely recovered after drying for the Kevlar ${ }^{\circledR} / e p o x y$ and partially recovered for the glass/epoxy. Gaur et al. [13] also observed during immersion a $21 \%$ increase in post-debonding frictional stress due to the pressure exerted by matrix swelling.

Similarly, the aging mechanisms in natural fibre composites in water have mostly been studied at the macroscale [14-19]. The fibre-matrix interface is often cited as a privileged region for degradation, resulting in a decrease in global composite mechanical properties. However, very few publications describe direct measurement of Interfacial Shear Strength degradation of natural fibre /matrix systems during immersion.

The aim of this paper is to draw a baseline of knowledge on the interfacial degradation mechanism of a flax fibre/epoxy system thanks to direct measurement using micro-scale debond tests. This information will be useful to predict the lifetime of natural fibre composites in wet environments, both for mechanical design and in order to improve Life Cycle Analysis (LCA) calculations. 


\section{Materials and Methods}

\subsection{Materials}

Flax fibres of the Hermès variety (harvested in 2003) were used in this study ; these have been extensively characterized in previous studies [20-22]. These fibres were taken from plants grown in France (Normandy), they were dew retted to help fibre extraction then scutched and hackled. It is important to note that no other treatment was applied to the fibres. Then, single fibres were manually extracted and adhesively bonded (Loctite Super glue) to rectangular aluminium supports $(10 \times 30 \mathrm{~mm})$ with an elliptical window ( $\left.\mathrm{L}_{\text {free }}=10 \mathrm{~mm}\right)$. Aluminium supports are used instead of cardboard supports to allow complete immersion of the sample without degradation of the support. The quality of the fibre/aluminium support bonding was checked after immersion and before characterization. Furthermore each sample was checked by optical microscopy, to measure diameter $\left(\mathrm{d}_{\text {average }}=16.3 \pm 3.5 \mu \mathrm{m}\right)$ and to avoid multiple fibres and defects.

The thermoset resin for micro-droplet formation was a DGEBA epoxy (AXSON Epolam 2020, with $32 \%$ by weight aliphatic amine hardener). This was post cured at $65^{\circ} \mathrm{C}$ for $14 \mathrm{~h}$ after polymerization at room temperature to complete the crosslinking process [23]. This post-cure temperature was chosen to minimize fibre degradation caused by removal of water [24].

\subsection{Debonding of micro-droplets}

The droplets were placed on the flax fibres using a single glass fibre which had been dipped in the epoxy resin. Microbond specimens were then checked under the microscope to control the droplet geometry, length and height. Samples with defects (kink bands on the fibre or lack of symmetry of the droplet) were systematically rejected. Besides being symmetrical, microdroplets need to be smaller than $150 \mu \mathrm{m}$ length otherwise the fibre will break. At least 20 specimens were tested for each test condition. Then the flax fibre with the epoxy microdroplet was mounted in the shearing device and continuously observed with a microscope. The fibre was pulled out of the droplet while the latter was constrained by the knife edges. The loading rate during debonding was $0.1 \mathrm{~mm} / \mathrm{min}$.

The drying kinetics of this geometry of fibre/polymer system are complex due to their small volume. Samples were removed from water just before testing, and the test lasted a few minutes in a controlled environment $\left(23^{\circ} \mathrm{C}\right.$ and $\left.\mathrm{RH}=50 \%\right)$. It was therefore assumed that drying was negligible during testing.

Force-displacement plots were recorded for each specimen, in order to determine the debonding force and the friction force. Figure 1 shows a typical plot for an epoxy microdroplet on a flax fibre.

The initial behaviour is quite linear as elastic energy accumulates up to a sudden drop in force. The maximum load corresponds to debonding. The stored energy is dissipated in the creation of an interfacial crack. The load does not drop to zero as frictional forces are present (Fig. 1). The values of $F_{\max }$ and $F_{\text {friction }}$ are used to calculate respectively the apparent shear strength by evaluating the linear regression slope of the plot of forces versus debonded area. The validity of this approach was checked using a method proposed by Miller et al. [25] (equation 1) which assumes uniform distribution of stress along the fibre/matrix interface :

$$
\tau=\frac{F}{\text { Embedded surface }}
$$


T corresponds to either the apparent shear strength $T_{\text {app }}$ or the friction strength $T_{\text {friction }} \mathrm{F}$ is either the debonding force or the friction force. The embedded surface area corresponds to the bonded area between the fibre and matrix and is calculated by multiplying the perimeter of the fibre (assuming a circular shape) by the microdroplet length.

\subsection{Aging conditions}

Flax fibre/epoxy microdroplet samples were immerged in a glass container containing deionized water at room temperature. A set of specimens was tested immediately after removal from water after the following immersion periods: $15 \mathrm{~min}, 840 \mathrm{~min}, 5160 \mathrm{~min}$ and $8100 \mathrm{~min}$. A second set was immersed for the same periods but after removal from water these were dried under vacuum for one week at room temperature $\left(T=23^{\circ} \mathrm{C}\right.$ and $\left.\mathrm{RH}=50 \%\right)$. Given the small matrix volume it is assumed that all the absorbed water was removed.

\subsection{Scanning Electron Microscope (SEM)}

All the debond specimens (20 for each immersion time) were examined in the SEM (Jeol JSM 6460 LV) after testing in order to observe damage and debonding mechanisms. The specimens were coated with a thin gold-palladium layer to avoid charging.

\section{Results and Discussion}

\subsection{Evolution of interfacial shear strength with aging time}

Fig. 2A and B shows a flax/epoxy micro-droplet system which has been subjected to immersion for 8100 min without debonding. No damage of the fibre /matrix interface is visible at this scale which indicates the validity of the following microbond tests.

Fig. 3A shows typical plots from debonding tests on flax fibre/epoxy samples after different immersion times in de-ionised water (the friction part of the curve has been shortened for clarity). Fig. 3B shows how the maximum force values recorded at debonding evolve with bonded surface area between fibre and matrix, for all the immersion conditions, Figure $3 \mathrm{C}$ shows the friction force plots.

Immersion in water does not change the initial behaviour, as all the plots present a similar elastic part up to rapid interfacial failure (Fig. 3A). In addition a linear relationship is observed between debonding force and the interface area (Fig 3B) as well as between the friction force and the bonding surface (Fig. $3 \mathrm{C}$ ). Table 1 presents the interfacial shear strength values obtained using Equation 1..

Fig. 4 shows how the apparent shear strength $\left(\mathrm{T}_{\text {app }}\right)$ varies with immersion time. The initial unaged value is $22.5 \pm 2.9 \mathrm{MPa}$ for flax/epoxy which is lower than the value of $29.3 \pm 2.4$ MPa measured on glass fibre/epoxy with the same equipment in a previous study [26]. This may be due to the presence of sizing on the glass fibres, which has been optimized over many years to ensure good fibre/matrix bonding.

The immersion of specimens results in a significant drop (-50\%) in the apparent shear strength from $22.5 \mathrm{MPa}$ to $11 \mathrm{MPa}$ between 0 and 1000 minutes aging (Fig. 4). Then, between 1000 and 8100 minutes, the value is more stable, changing from $11 \mathrm{MPa}$ to 9.3 $\mathrm{MPa}$, so the additional exposure to water does not appear to induce further degradation.

Similar behaviour has been observed for glass/epoxy [13][111] and glass/polyester [27] with an initial rapid drop in interfacial strength. 
Drying allows part of the properties to be recovered, particularly after short immersion times (<840 min), (Fig. 4 white symbols). Gaur et al. [13] and Gautier et al. [27] have shown identical behaviour for glass/epoxy and glass/polyester systems. Once again the $\operatorname{Kevlar}^{\circledR} /$ Epoxy shows a different trend, with complete recovery of apparent shear strength after drying [13]. After longer immersion times (>840 $\mathrm{min}$ ), the forces responsible for ensuring the adherence of flax fibres to epoxy show good durability in an aqueous environment.

Fig. 5A, B, C, D, E, F, G and $\mathrm{H}$ show fracture surfaces after debonding for unaged specimens (Fig. 5A and B), aged for $8100 \mathrm{~min}$ (Fig. 5C, D, E and F) and aged for $8100 \mathrm{~min}$ then dried (Fig. 5G and $\mathrm{H}$ ).

Cohesive failures in the matrix, in the form of a residual epoxy meniscus left on the flax fibre, are visible on $100 \%$ of the unaged specimens (Fig.5A and B) while these are less apparent after aging. Specimens immerged for 8100 min show only $20 \%$ of this type of failure (Fig.5C and D).

The presence of a residual epoxy meniscus after debonding (Fig. 5A and B) confirms crack initiation in mode I in the droplet as a result of the radial normal stress distribution along the fibre/matrix interface $[28,29]$. The change in the failure mode after aging could be related to the lower maximum forces for these specimens, due to the lower fibre/matrix bond strength. Moreover it indicates that the distribution and amplitude of these radial stresses is modified. The water uptake and resulting plasticization may cause relaxation of thermal residual stresses and reduce the pressure exerted by the matrix on the fibre [13], [30, 31]. The change in failure mode can also be explained by a more pronounced degradation of the resin at the ends of the micro-droplet, due to a smaller volume of material. Indeed geometric parameters such as thickness affect the degradation kinetics of the resin through hydrolytic degradation and exudation mechanisms.

Reversible aging phenomena at short immersion times $(<840 \mathrm{~min})$ is caused by plasticization of the fibre/matrix interface. Indeed certain components on the fibre surfaces such as pectins and hemicelluloses are also sensitive to water and their glass transition temperature is modified by humidity $[32,33]$.

After longer immersion times (>840 min), the good durability of the forces responsible for ensuring the adherence of flax fibres to epoxy is due to reactive functions of the epoxy matrix such as amine and epoxyde, which are capable of creating strong and durable bonds with hydroxyl groups on the flax fibre surface. However, irreversible degradation dominates and drying no longer allows properties to be recovered (Fig. 4). This may be due to water condensation at the interfaces [8] explained by interactions between polar sites of the matrix and hydroxyl groups. Indeed, Kinloch [7] proposed for synthetic materials that above a certain critical quantity of water at an interface the reversible work of adhesion $\mathrm{W}_{\mathrm{a}}$ is modified and passes from positive (a stable system) to negative (unstable). This results in a force which is capable of breaking the secondary bonds at the interface between the fibre and matrix.

Uncrosslinked epoxy molecules can be washed out of the matrix during immersion, particularly in deionized water [13]. Bourmaud et al. [34] noted during immersion of flax fibres (distilled water at $23^{\circ} \mathrm{C}$ for $72 \mathrm{~h}$ ) that certain fibre surface components such as pectins (homogalacturonan) or components partially hydrolyzed during retting (galactose) are dissolved in water. Therefore when these components are located at the fibre/matrix interface and when dissolution occurs, voids may be generated. In addition, when such surface impurities are soluble Cognard et al. [8] have suggested that an osmotic pressure can develop in the interphase area, and damage can be created which accumulates to form cracks at the interface. 
In addition, partially cohesive fibre failures including peeling of one or more cell-walls of the fibre, can be seen on the aged samples (Fig. 5E and F). This makes it more difficult to define the broken surface accurately and therefore leads to variability in the interfacial shear strength. For this reason a comparative analysis is preferred. Specimens which have been dried after immersion show a particular fracture surface with many fibrillar features (Fig. 5G and $H$ ). This is the result of more superficial surface peeling compared to that observed for aged samples (Fig 5E and F).

Fig. 6A shows a schematic representation of a microdroplet on a single flax fibre. The flax fibre has a multilayer structure (primary cell wall, secondary wall (S1, S2 and S3)) with several interphase regions between these bonded layers (Fig. 6B). These interphase zones correspond to composition transitions, changes in structure (microfibril orientation) as well as properties [35].

The cell wall peeling phenomena observed after aging will occur in the weakest part of the interfacial region inside the flax fibre (figure 6B). Thus the bonds which control the adherence between cell walls, though not fully understood, are sensitive to water.

Natural fibres are composed of polysaccharides which correspond respectively to residual middle lamellae on their surface and components which play the role of a matrix by coating the cellulose fibrillar structure within the fibres. These include pectins and hemicelluloses that have high polar components of their surface energy [26], which favour the formation of hydrogen bonds with water. In addition water penetrates the amorphous regions, may diffuse along lumen paths and reduces the interactions between crystalline and amorphous zones [36]. This induces reduction of their mechanical properties [20] which could weaken the interlayer cohesion.

\subsection{Evolution of the friction strength}

Post-debonding friction is rarely analyzed for these tests, but it can provide additional information on the level of residual thermal stresses induced by differential thermal expansion between components and resin shrinkage due to polymerization. Fig. 7 shows how the friction strength evolves with immersion time.

First it may be noted that the friction strength is quite high $(6.7 \pm 1.9 \mathrm{MPa})$ before immersion. This is close to values measured previously on flax/PLLA (7.7 $\pm 1.5 \mathrm{MPa})$ and glass/epoxy $(7.7 \pm 1.4 \mathrm{MPa})$ during similar tests $[21,26]$. The friction strength follows a similar trend to that of the apparent debonding shear strength, with a large drop (>-50\%) after short immersion times ( $<840 \mathrm{~min}$ ) which may be due to a lubricating effect of water. Then a stabilization occurs at longer times (Fig. 7).

These results differ from those of Pandey et al. [12] and Biro et al. [30] on carbon/epoxy systems respectively immersed in boiling water and water at $80^{\circ} \mathrm{C}$. Biro et al.[30] found an increase in friction strength (by more than 200\%) and in the friction contribution to $\mathrm{T}_{\text {app }}$ after immersion. They explained their results by matrix swelling and an increase in the surface roughness of the fibres [30]. For the flax system the washing-off of the fibre surface components (pectins...) results in a decrease in surface roughness measured by Atomic Force Microscopy [20]. However, in a previous study the cleaning of flax fibres of the same variety with a water treatment was shown not to cause a drop in friction strength for a Flax/PLLA system [20]. Moreover, the ratio $T_{\text {friction }} / T_{\text {app }}$ decreases with aging duration (table 2) from around $30 \%$ initially to $20 \%$ after immersion for 8100 minutes. It may be therefore that the removal of surface components which contribute to interfacial reactions, rather than the reduction in roughness, explains the loss in friction strength. 
This drop in friction strength was unexpected as the difference in swelling expansion between fibre and matrix should result in the development of increased hygroscopic stresses after immersion. Mwaikambo et al. [37] suggest that swelling of plant fibres can exert high stresses on the matrix. However in our case, no initial damage was observed (Fig. 2) suggesting that hygroscopic stresses due to differential swelling between fibre and matrix are low. There are several possible explanations. First, the fibres are pre-stressed, by a radial pressure resulting from the difference in thermal expansion coefficients, which results in lower weight gain and lower swelling pressure [38]. Also, Perkitny and Kingston [39] indicate a large reduction in swelling stresses when the system is only partially constrained, which is the case here (the fibre is free to move in the longitudinal direction). Bolton et al. [40] suggest that when wet wood is plasticized, the swelling pressure is negligible. Finally, the hierarchical multilayer fibre structure, its porous nature, the presence of a lumen, and the strong anisotropy may lead to a collapse of the fibre structure as transverse compression properties may decrease during immersion. This may also explain the presence of cracks on the fibres (Fig 5D).

\subsection{Descriptive model of the properties of the $\left(\tau_{a p p}\right.$ and $\left.T_{\text {friction }}\right)$ versus immersion time}

In order to identify the characteristic transition time of degradation kinetics of flax/epoxy microcomposites and to describe the evolution of interfacial properties during immersion a simple phenomenological model is proposed as follows [41]:

$\tau=\left((\tau(0)-\tau(\infty)) \exp \left[-\frac{t}{t c}\right]+\tau(\infty)\right.$

where $\mathrm{T}$ is the apparent shear strength or the friction strength, $\mathrm{T}(0)$, the strength (apparent shear or friction) before immersion, $\mathrm{T}(\infty)$ is the apparent shear strength (or friction strength) after an infinitely long immersion time, $t$ is the immersion duration, and $t_{c}$ the characteristic time corresponding to a change in degradation kinetics.

Fitting the data to this simple model does not give additional information on the degradation mechanisms but can indicate transitions in degradation kinetics (Fig 4 and Fig. 7). Table 3 shows the values identified for apparent shear strength and friction strength.

The residual strength after an infinitely long immersion time $T_{\text {app }}(\infty)$ corresponds to adherence mechanisms which show good durability under long term wet aging conditions. This suggests that the mechanisms are at least partially based on strong covalent bonds due to reactive sites of the matrix (amine and epoxyde) and the fibre surface (hydroxyls).

The transition time $t_{c}$, is identified to be around 15 hours (900 min) which is close to the transition time corresponding to the change in behaviour from degradation to stabilization (Fig. 4 and Fig. 7). Pillut-lesavre [31] suggests that this change corresponds to the diffusion time necessary for water to reach the fibre/matrix interface. Kinloch [7] propose that a critical amount of water is needed at an interface to cause debonding. It is interesting to examine whether such a critical water level can be related to the transition time $t_{c}$, identified here by the water diffusion kinetics either through the matrix resin or along the fibre.

In order to estimate the time needed for water diffusion through the epoxy, the micro-droplet can be simulated by co-axial cylinders as shown below (Fig. 8A), to simplify the calculation. In this case the water diffusion distance from the surface of the droplet to the fibre/matrix interface is similar whatever the location in the surface and is equal to the radius of the cylinder. 
The path followed by the water through the droplet to reach the fibre/matrix interface is then half the cylinder area and the penetration time $\mathrm{t}_{1 \mathrm{c}}$ (figure 8B) can be approximated by:

$\mathrm{t}_{1 \mathrm{c}}=\pi(\mathrm{R}-\mathrm{r}) \cdot \mathrm{L} / \mathrm{D}$

where $\mathrm{R}$ is the mean radius of the epoxy cylinder, equal here to the mean droplet radius $(37.2 \pm 8.2 \mu \mathrm{m}), r$ the mean fibre radius $(8,15 \pm 1.75 \mu \mathrm{m}), L$ the mean bonded length $(124 \pm$ $26 \mu \mathrm{m})$ and $D$ diffusion coefficient for deionised water in this epoxy resin at ambient temperature $\left(D=0.047 \mu \mathrm{m}^{2} / \mathrm{s}\right.$ [42]). This calculation results in a value of $t_{1 \mathrm{c}}$ of around 67 hours (around $4000 \mathrm{~min}$ ), much longer than the observed and calculated time at which the loss of properties become irreversible (around 840 minutes according to Fig. 4 and 900 minutes according to Eq. 2).

However, this approach only treats the case of water passing through the droplet, it does not take into account the fact that the flax fibres absorb water. Water can therefore also diffuse along the interface via the fibre. By modifying equation 3 to estimate the time $t_{2 c}$ taken by the water to diffuse all the way along the fibre/matrix interface (figure $8 \mathrm{~B}$ ) we obtain equation 4 :

$\mathrm{t}_{2 \mathrm{c}}=(\pi \cdot \mathrm{r} \cdot \mathrm{L}) / 2 \mathrm{D}$

With $D$ the diffusion cœfficient for deionized water in a flax fibre at $25^{\circ} \mathrm{C}\left(\mathrm{D}=0.6510^{-8} \mathrm{~cm}^{2} / \mathrm{s}\right.$ [43]).

In this case the critical time $t_{2 C}$ is around 40 minutes. This is lower value than tc calculated from Eq. 2 and much shorter than the time needed for diffusion to the interface through the epoxy droplet thickness. It underlines the rapid water diffusion along natural fibres/matrix interfaces, and suggests that the mode change is caused by the time required for plasticization of the matrix droplet coupled with the change in stress state as water enters the epoxy (matrix cohesive failure), so that degradation of the outer fibre layers (fibre cohesive failure) occurs.

To develop this analysis in more detail would require not only properties for the capillary diffusion along the interface but also a more complex model of water transport through the multiple layers and the lumen of the fibre.

\section{Conclusion}

Understanding the parameters which govern the durability of biocomposites is important for Eco-design. The fibre/matrix interface is a critical zone for composite long term performance while natural fibres are particularly sensitive to moisture. In this paper aging tests have been performed on flax fibre/ epoxy micro-droplets in order to examine the interfacial degradation mechanisms directly.

Prior to aging :

The values of apparent shear strength for the flax fibre/epoxy system are lower than values for glass/epoxy but remain high, showing that natural fibres are not necessarily incompatible with polymers as is sometimes suggested in published papers.

During aging : 
- Apparent shear strength drops quickly then stabilizes. Mechanical property reduction is initially reversible with plasticization dominating.

- At longer times reduction of IFSS is permanent but some adherence remains between flax and epoxy. Permanent degradation mechanisms include dissolution of flax fibre constituents (pectins ...). In addition, SEM micrographs reveal fibre peeling after aging, indicating the need to include intrinsic fibre layer bonding in the interfacial analysis.

- Analysis of friction reveals a drop in friction strength with increasing immersion time due to the lubricating effect of water and possible washing-out of surface pectins from the flax fibres.

- A simple descriptive model has been used to identify diffusion kinetics, with a critical diffusion time corresponding to a change in degradation mechanism.

\section{Acknowledgement.}

The authors are grateful to Antoine Kervoelen, Alain Bourmaud and Mickael Castro for their contributions to this study.

\section{References}

1. Ashby, M., Materials Selection in Mechanical Design- 2nd edition. Reed Educational \& Professional Publishing, ed. Butterworth-Heinemann. 1999.

2. Le Duigou, A., P. Davies, and C. Baley, Environmental impact analysis of the production of flax fibres to be used as composite material reinforcement. J. biobased. mater.bioenerg., 2011. 5: p. 1-13.

3. Patel, M., C. Bastioli, L. Marini, and E. Wurdinger, Environmental assessement of bio based polymers and natural fibers, in encyclopedia "Biopolymers", C. Bastioli, Editor. 2002. p. 409-452.

4. Le Duigou, A., P. Davies, and C. Baley, Replacement of glass/unsaturated polyester composites by flax/PLLA biocomposites : Is it justified? J. biobased mater. bioenerg., 2012. 5(4): p. 466-482.

5. Kim, S., B. Dale, L. Drzal, and M. Misra, Life cycle assessment of kenaf fiber reinforced biocomposite. J. of biobased mater. bioenergy, 2008. 2(85-93).

6. Bordès, M., Etude du vieillissement des liaisons adhésives en milieu marin pour application offshore. Thesis Report (In french) IFREMER, 2009.

7. Kinloch, A., Adhesion and Adhesives. Adhesion and Adhesives-Science and Technology, Chapman and Hall, 1987.

8. Cognard, J., Science et Technologie du collage. Presses polytechniques et universitaires romandes., 2000.

9. Joseph, P.V., M.S. Rabello, L.H.C. Mattoso, K. Joseph, and S. Thomas, Environmental effects on the degradation behaviour of sisal fibre reinforced polypropylene composites. Comp. Sci Technol., 2002. 62(10-11): p. 1357-1372.

10. Zinck, P., De la caractérisation micromécanique du vieillissement hydrothermique des interphases polyepoxyde-fibre de verre au comportement du composite unidirectionnel. Relations entre les echelles micro et macro, in Thesis report ILMM UMR CNRS 5627 INSA. 1999, Lyon: Lyon. 
11. Zinck, P. and J. Gerard, Thermo-hydrolytic resistance of polyepoxide glass fibres interfaces by the microbond test. Com. Sci.Technol., 2008. 68(9): p. 2028-2033.

12. Pandey, G., C. Kareliya, J. Hinkley, and R. Singh, Interfacial micromechanics and effect of moistue on fluorinated epoxy carbon fibre composites. Polym. comp., 2011. 32(12): p. 1961-1969.

13. Gaur, U. and B. Miller, Effects of environmental exposure on fiber/epoxy interfacial shear strength. Polym. comp., 1990. 11(4): p. 217-222.

14. Islam, M.S., K.L. Pickering, and N.J. Foreman, Influence of accelerated ageing on the physico-mechanical properties of alkali-treated industrial hemp fibre reinforced poly(lactic acid) (PLA) composites. Polym Degrad and Stab, 2010. 95(1): p. 59-65.

15. Dhakal, H.N., Z.Y. Zhang, and M.O.W. Richardson, Effect of water absorption on the mechanical properties of hemp fibre reinforced unsaturated polyester composites. Comp. Sci. Technol., 2007. 67(7-8): p. 1674-1683.

16. Le Duigou, A., P. Davies, and C. Baley, Seawater aging of Flax/PLLA biocomposite. Polymer Degradation and Stability, 2009. 94: p. 1151-1162.

17. Le Duigou, A., J. Deux, P. Davies, and C. Baley, Protection of Flax/PLLA Biocomposites from Seawater Ageing by External Layers of PLLA. Int. J. Polym. Sci., 2011. 2012(doi:10.1155/2011/235805).

18. Yew, G.H., A.M. Mohd Yusof, Z.A. Mohd Ishak, and U.S. Ishiaku, Water absorption and enzymatic degradation of poly(lactic acid)/rice starch composites. Polym Degrad and Stab, 2005. 90(3): p. 488-500.

19. Stamboulis, A., C.A. Baillie, S.K. Garkhail, H.G.H. van Melick, and T. Peijs, Environmental Durability of Flax Fibres and their Composites based on Polypropylene Matrix. App. Comp. Mater., 2000. 7(5): p. 273-294.

20. Le Duigou, A., A. Bourmaud, E. Balnois, P. Davies, and C. Baley, Improving the interfacial properties between flax fibres and PLLA by a water fibre treatment and drying cycle. Ind. Crops Prod., 2012. 39: p. 31-39.

21. Le Duigou, A., P. Davies, and C. Baley, Interfacial bonding of flax/Poly(L-Lactide) biocomposites. Composites Science and Technology, 2010. 70(2): p. 231-239.

22. Charlet, K., C. Baley, C. Morvan, J.P. Jernot, M. Gomina, and J. Bréard, Characteristics of Hermès flax fibres as a function of their location in the stem and properties of the derived unidirectional composites. Comp. Part A: App. Sci., 2007. 38(8): p. 1912-1921.

23. Baley, C., Y. Grohens, F. Busnel, and P. Davies, Application of interlaminar test to marine composites. Relation between glass fibre/polymer interfaces and interlaminar properties of marine composites. Applied Composite Materials, 2004. 11: p. 77-98.

24. Baley, C., A. Le Duigou, A. Bourmaud, and P. Davies, Influence of drying on the mechanical behaviour of flax fibres and their unidirectional composites. Compos. Part A: Appl. Sci., 2012(0).

25. Miller, B., A microbond method for determination for determination of the shear strength of a fiber/resin interface. Comp. Sci. Technol., 1987. 28: p. 17-32.

26. Baley, C., F. Busnel, Y. Grohens, and O. Sire, Influence of chemical treatments on surface properties and adhesion of flax fibre-polyester resin. Composite Part A: Applied Science and Manufacturing, 2006. 37(10): p. 1626-1637.

27. Gautier, L., B. Mortaigne, and V. Bellenger, Interface damage study of hydrothermally aged glass-fibre-reinforced polyester composites. Comp. Sci. Technol., 1999. 59(16): p. 2329-2337.

28. Zinck, P., H.D. Wagner, L. Salmon, and J.F. Gerard, Are microcomposites realistic models of the fibre/matrix interface? I. Micromechanical modelling. Polym., 2001. 42(12): p. 5401-5413.

29. Herrera-Franco, P. and L. Drzal, Comparison of methods for the measurement of fibre/matrix adhesion in composites. Comp. Sci. Technol., 1992. 23(1): p. 2-27.

30. Biro, D., G. Pleizer, and Y. Deslandes, Application of the microbond technique : Effects of hygrothermal exposure on carbon fiber/epoxy interfaces. Comp. Sci. Technol., 1993. 46: p. 293-301. 
31. Pillut-lesavre, Influence de l'interphase sur le vieillissement des composites à matrice propargyl-chromène. Thesis report Université Claude Bernard Lyon 1, 1998.

32. Tissaoui, J., Effects of Long-Term Creep on the Integrity of Modern Wood Structures. http://scholar.lib.vt.edu/theses/public/etd-12803097520/etd.pdf, 1996.

33. Davies, G.C. and D.M. Bruce, Effect of Environmental Relative Humidity and Damage on the Tensile Properties of Flax and Nettle Fibers. Textile Research Journal, 1998. 68(9): p. 623-629.

34. Bourmaud, A., C. Morvan, and C. Baley, Importance of fiber preparation to optimize the surface and mechanical properties of unitary flax fiber. Industrial Crops and Products, 2010. 32(3): p. 662-667.

35. Roland, J., M. Mosiniak, and D. Roland, Dynamique du positionnement de la cellulose dans les parois des fibres textiles du lin (Linum Usitatissimum). Acta Bot. Gallica, 1995. 142(5): p. 463-484.

36. Astley, A. and A. Donald, A small angle scattering X-ray study of the effect of hydration on the microstructure of flax fibers. Biomacromolecules, 2001. 2: p. 672680.

37. Mwaikambo, L. and M. Ansell, Chemical modification of hemp, sisal, jute and kapok fibers by alkalization. J. App. Polym. Sci., 2001. 84: p. 2222-2234.

38. Perkitny, T. and L. Helinska, Swelling pressure of wood in water and water saturated air. Holz Roh-Werkst, 1963. 21: p. 19-22.

39. Perkitny, T. and R. Kingston, Review of the sufficiency of research on the swelling pressure of wood. Wood. Sci. Technol., 1972. 6(215-229).

40. Bolton, A., P. Jardine, M. Vine, and W. JCF., The swelling of wood under mechanical restraint. Holzforschung, 1974. 28: p. 138-145.

41. Hassoune-Rhabbour, B., Y. Baziard, V. Nassiet, and J. Petit, Durabilité des assemblages collés- Approche prédictive. Technique de l'ingénieur- COR 161, 2006.

42. Bordes, M., P. Davies, J.-Y. Cognard, L. Sohier, V. Sauvant-Moynot, and J. Galy, Prediction of long term strength of adhesively bonded steel/epoxy joints in sea water. Int. J. Adhesion and Adhesives, 2009. 29(6): p. 595-608.

43. Gouanvé, F., S. Marais, A. Bessadok, D. Langevin, and M. Métayer, Kinetics of water sorption in flax and PET fibers. Europ. Polym. J., 2007. 43(2): p. 586-598.

\section{Tables}

Table 1: Apparent shear strength from Equation 1

\begin{tabular}{|c|c|c|}
\hline Immersion time (min) & $\tau_{\text {app }}$ from Eq. 1 & Standard deviation \\
\hline 0 & 22.5 & 2.1 \\
\hline 15 & 15.0 & 4.0 \\
\hline 840 & 11.1 & 3.8 \\
\hline 5160 & 8.2 & 1.0 \\
\hline 8100 & 8.9 & 1.1 \\
\hline
\end{tabular}


Table 2 : Friction strength calculated from Equation 1 and contribution of the friction strength to the apparent shear strength (\%)

\begin{tabular}{|c|c|c|c|c|}
\hline $\begin{array}{c}\text { Immersion time } \\
(\mathrm{min})\end{array}$ & $\begin{array}{c}\tau_{\text {Friction }}(\mathrm{MPa}) \\
\text { from eq. } 1\end{array}$ & $\begin{array}{c}\text { Standard } \\
\text { deviation }\end{array}$ & $\tau_{\text {Friction }} \tau_{\mathrm{App}}(\%)$ & $\begin{array}{c}\text { Standard } \\
\text { deviation }\end{array}$ \\
\hline 0 & 6,7 & 1,9 & 29,2 & 3 \\
\hline 15 & 3,8 & 1,4 & 25,3 & 5,4 \\
\hline 840 & 2,8 & 1,6 & 25,2 & 5,4 \\
\hline 5160 & 1,45 & 0,9 & 17,7 & 1,9 \\
\hline 8100 & 1,7 & 0,7 & 19,1 & 1,8 \\
\hline
\end{tabular}

Table 3 : Parameters to evaluate the changes in apparent shear strength and friction strength with immersion time

\begin{tabular}{|l|l|l|l|}
\hline & $\tau(\mathrm{o})(\mathrm{MPa})$ & $\tau(\infty)(\mathrm{MPa})$ & $\mathrm{t}_{\mathrm{c}}$ (Hours) \\
\hline Model $\tau_{\text {app (wet) }}$ & $21.7 \pm 2.5$ & $9.5 \pm 0.8$ & $17 \pm 5$ \\
\hline Model $\tau_{\text {friction (wet) }}$ & $6.7 \pm 1.2$ & $2.0 \pm 0.4$ & $15 \pm 5$ \\
\hline
\end{tabular}

\section{Figures}

Figure 1 : Typical debonding curve for unaged flax/epoxy specimen

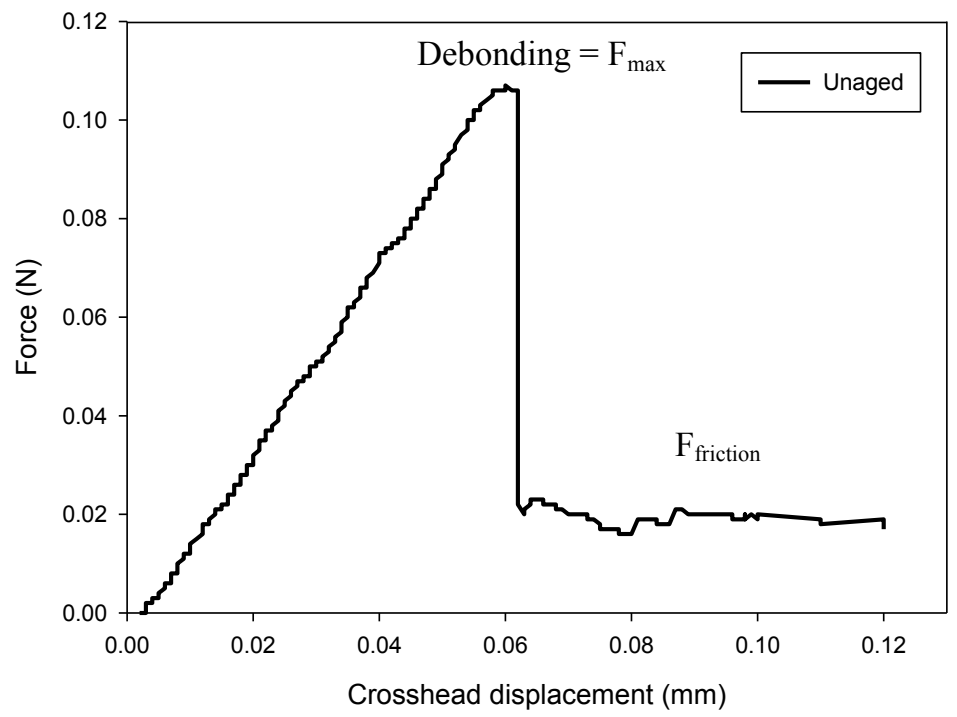


Figure 2A : SEM micrographs of an untested epoxy microdroplet on a single flax fibre after immersion for 8100 min- B Detail of meniscus.
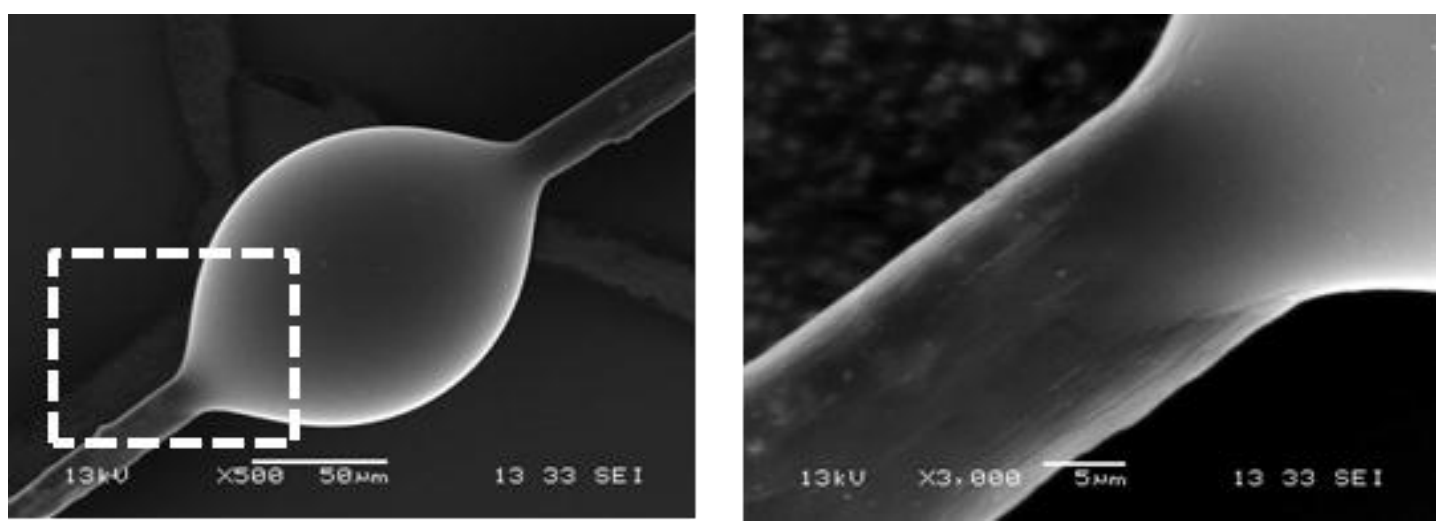

Figure 3A : Typical force-crosshead displacement curves for flax/epoxy system according to aging time. B Microbond peak load versus embedded area for flax/Epoxy at various immersion time- C Microbond friction load versus embedded area for flax/Epoxy at various immersion time
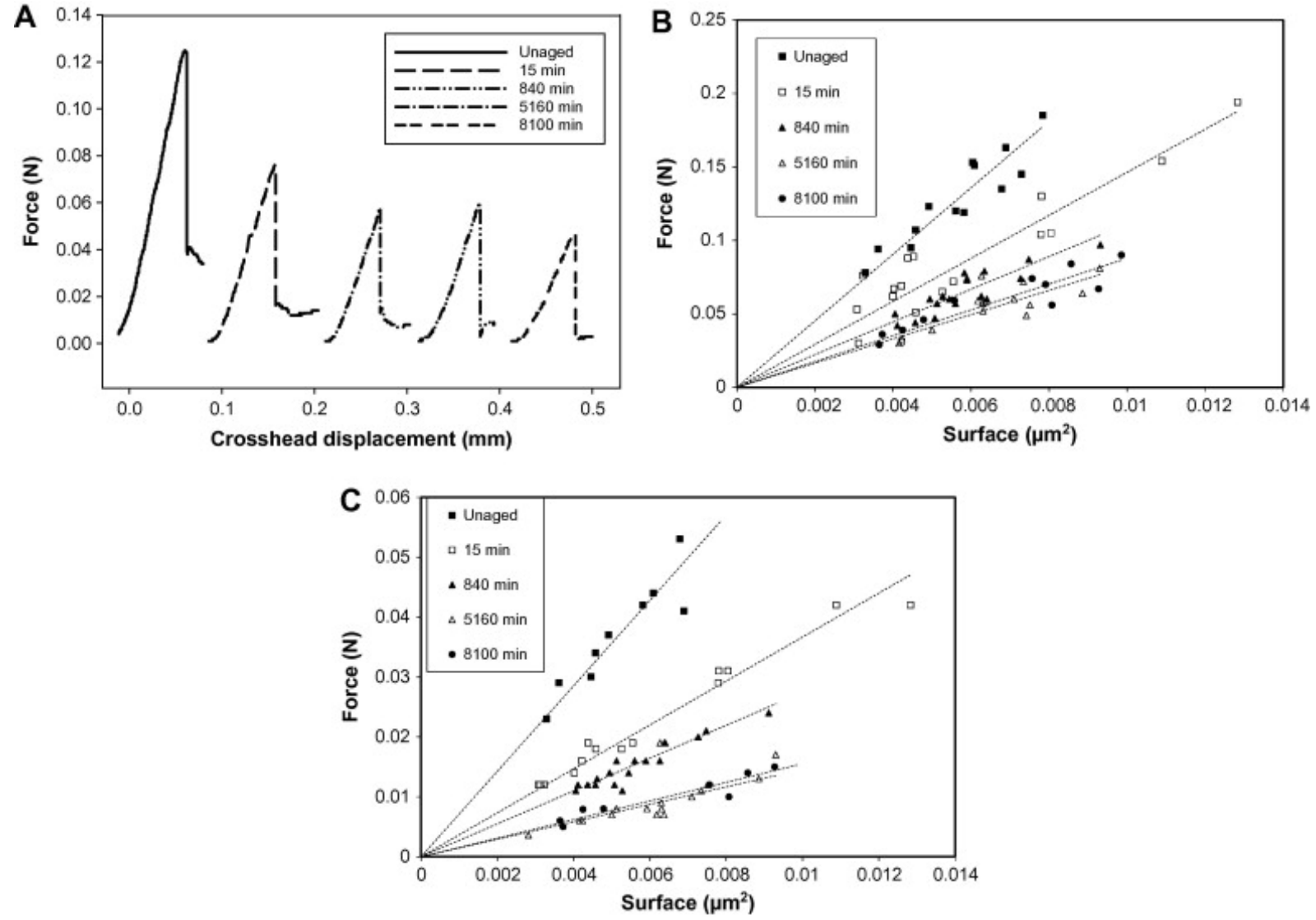
Figure 4 : Evolution of apparent shear strength with immersion time for wet aged samples (Black symbols) and wet aged and dried (white symbols).

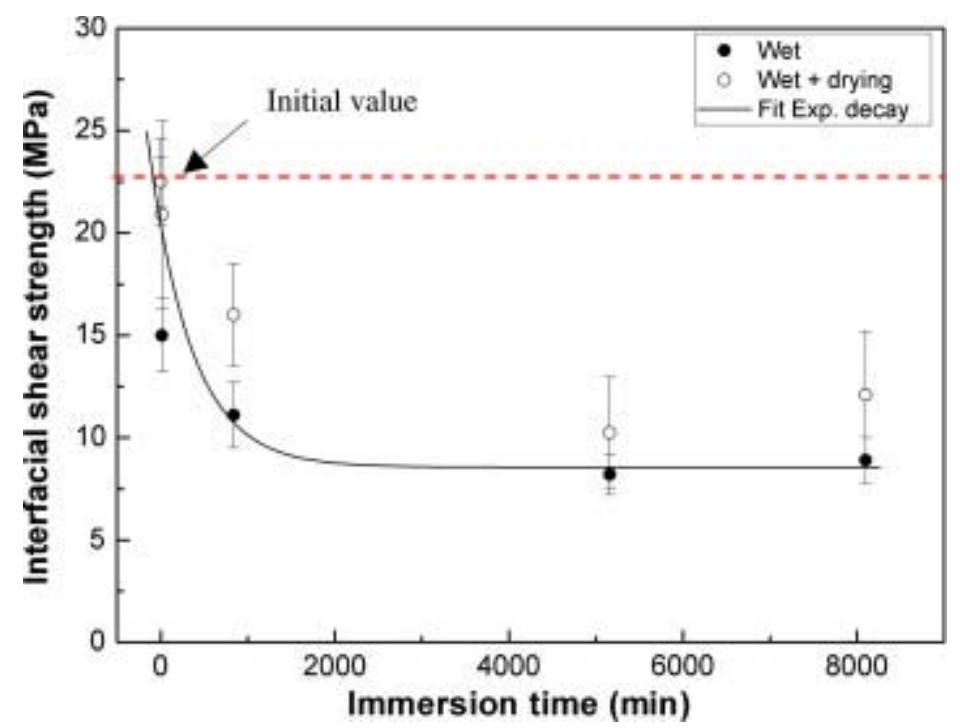


Figure 5 : SEM micrographs of fractured unaged microbond specimens (A and B), 8100 min aged samples (C, D, E and $F)$ and 8100 min aged then dried ( $G$ and $H)$
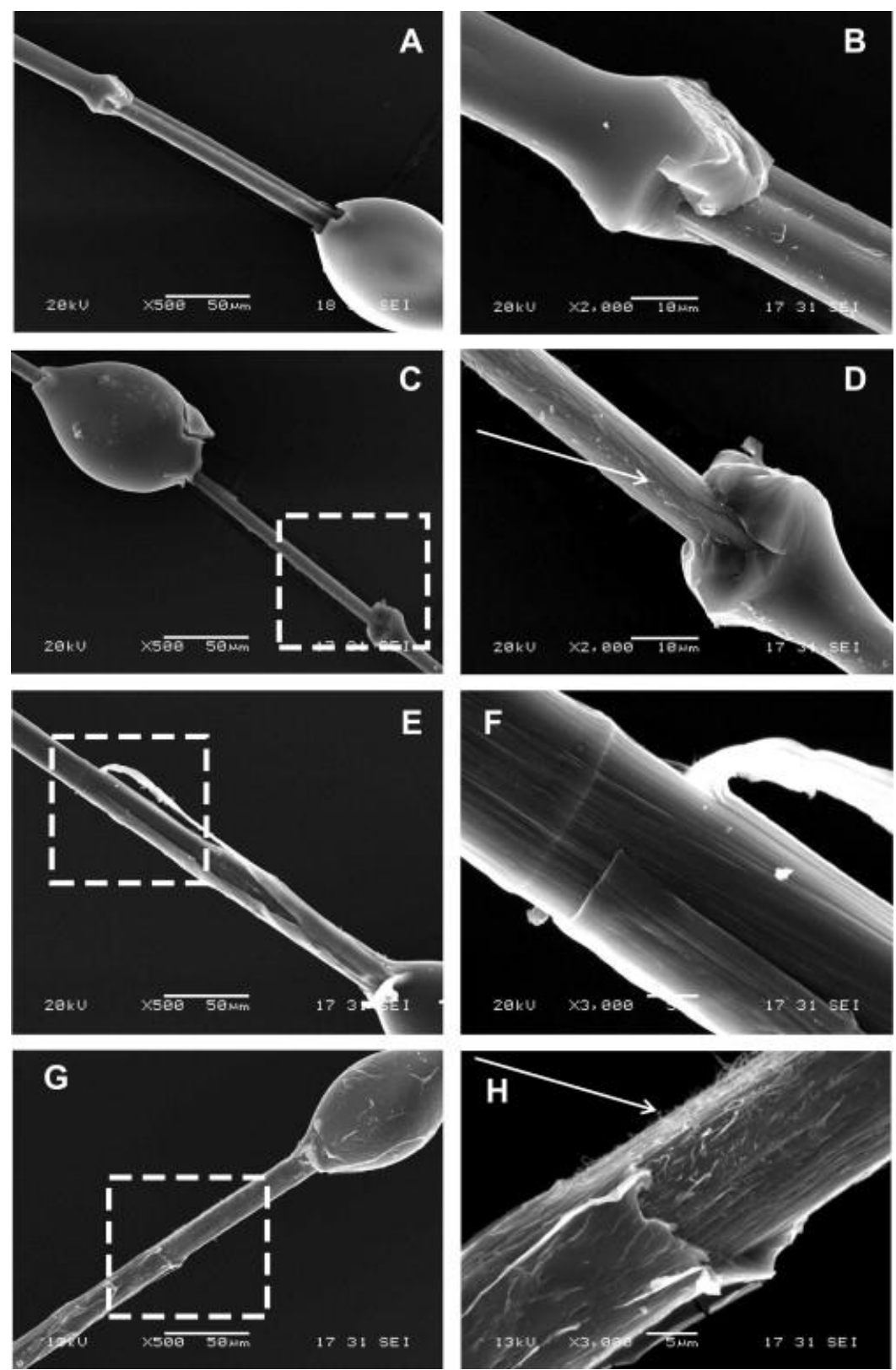
Figure 6A : schematic view of single flax fibre/epoxy microdroplet. B Schematic view of multilayer structure of flax fibre (Primary Cell Wall (PCW), Secondary Cell Wall (SCW))
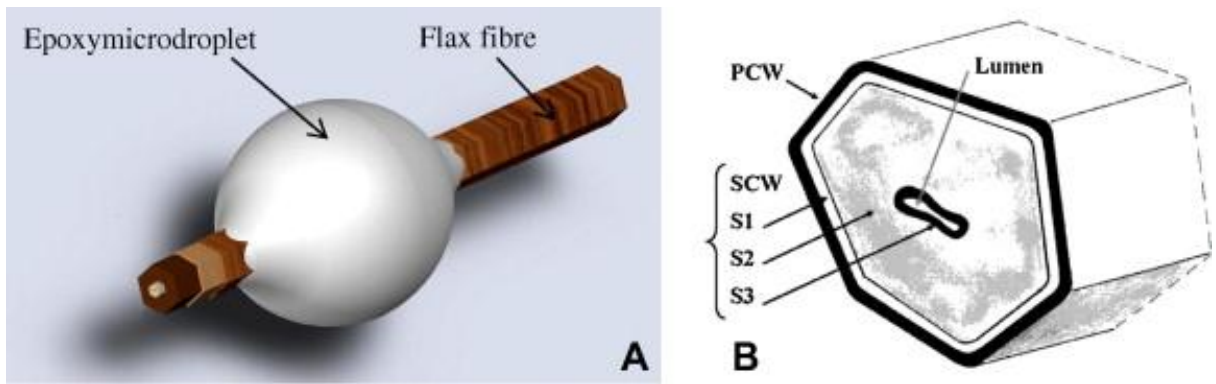

Figure 7 : Evolution of friction strength with immersion time for aged systems (Black symbols) and aged and dried (white symbols).

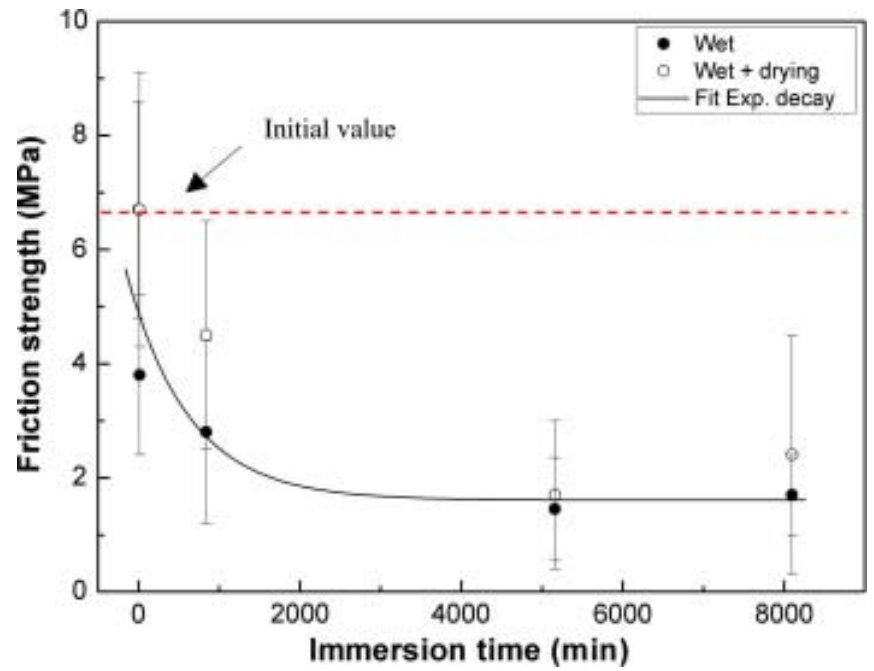

Figure 8A : Cylindrical model of epoxy microdroplet. B-Schematic drawing of the diffusion paths
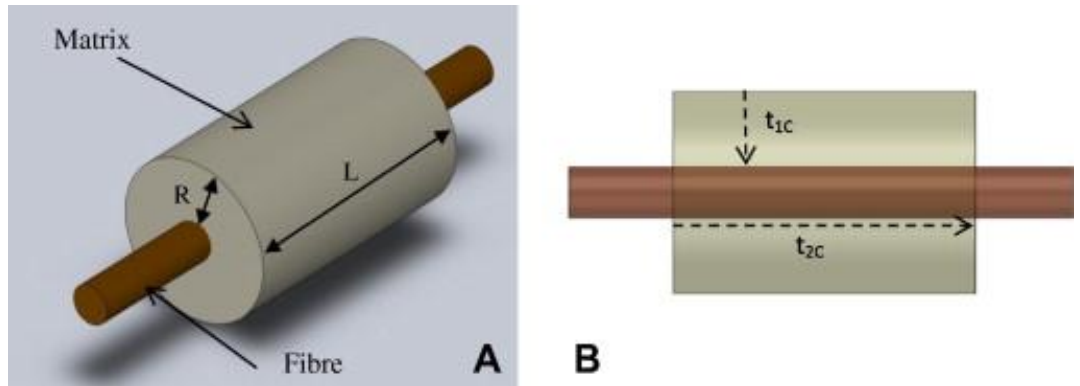

A B 